\title{
Efficacy of various antioxidants in the protection of the retinal pigment epithelium from oxidative
}

\section{stress}

This article was published in the following Dove Press journal:

Clinical Ophthalmology

6 September 2012

Number of times this article has been viewed

\section{Dov B Kagan \\ Hong Liu \\ Cindy ML Hutnik}

Ivey Eye Institute, St Joseph's Hospital, London, ON, Canada
Correspondence: Cindy ML Hutnik Department of Ophthalmology, Ivey Eye Institute, St Joseph's Hospital, 268 Grosvenor Street, London,

ON N6A 4V2, Canada

$\mathrm{Tel}+\mathrm{I} 5196466272$

Fax +I 5196466410

Email cindy.hutnik@sjhc.london.on.ca
Background: Oxidative stress induced retinal pigment epithelium (RPE) dysfunction is hypothesized to be fundamental in the pathogenesis of age-related macular degeneration (AMD). This study investigated whether vitamin C, vitamin C phosphate, vitamin E, propofol, betaxolol, and $\mathrm{N}$-acetyl cysteine (NAC) protect human RPE cells from oxidative stress.

Methods: ARPE-19 cells were pretreated with the compounds under investigation. The chemical oxidant tert-butyl hydroperoxide (t-BOOH) was used to induce oxidative stress. Cell viability was determined using the 3-(4,5-dimethylthiazol-2-yl)-2,5-diphenyltetrazolium bromide (MTT) assay.

Results: Exposure to t-BOOH resulted in a dose- and time-dependent reduction in ARPE-19 cell viability. Compared with cells given t-BOOH alone, vitamin E and NAC pretreated cells had significantly improved viability, propofol and betaxolol pretreated cells had no significant difference in viability, and vitamin $\mathrm{C}$ and vitamin $\mathrm{C}$ phosphate pretreated cells had significantly reduced viability.

Conclusion: Of the compounds studied, only vitamin E and NAC significantly mitigated the effects of oxidative stress on RPE cells. Because of their potential therapeutic value for AMD patients, these and other RPE protective compounds continue to merit further investigation.

Keywords: age-related macular degeneration, N-acetyl cysteine, vitamin C, vitamin E, propofol, betaxolol

\section{Introduction}

Age-related macular degeneration (AMD) is one of the leading causes of blindness in the Western world. ${ }^{1}$ AMD is characterized by a loss of photoreceptors in the central retina associated with dysfunction of the retinal pigment epithelium (RPE), Bruch's membrane, and the choroid. ${ }^{2}$ Disruption of the homeostatic function of the RPE is believed to be fundamental in the pathogenesis of AMD. ${ }^{2}$ Damage resulting from an excess of reactive oxygen species (ROS), known as oxidative stress, is hypothesized to contribute to RPE injury. ${ }^{2,3}$ Older age, a major risk factor for AMD, ${ }^{4}$ results in increased oxidative stress due to higher ROS production and diminished antioxidant defenses. ${ }^{2,3}$ The retina is particularly susceptible to ROS formation due to its high consumption of oxygen, constant exposure to light, and abundance of polyunsaturated fatty acids. ${ }^{3}$

Antioxidant supplementation has been proposed as a method of reducing oxidative stress induced damage to the retina. ${ }^{3}$ There is evidence that a variety of compounds protect the RPE against oxidative stress, including carotenoids, flavonoids, zinc, and vitamins A, C, and E. ${ }^{3,5,6}$ Clinically, the Age Related Eye Disease Study (AREDS) reports that dietary supplementation with a multivitamin formula, both alone and in 
combination with zinc, slows the progression of AMD in patients with advanced stages of the disease. ${ }^{7}$

Nevertheless, currently available compounds have limitations necessitating investigation into alternative retinal protective agents. The AREDS reports that neither multivitamin nor zinc supplementation slows the progression of early stage AMD. ${ }^{7}$ High-dose vitamin supplementation may also be harmful in the long term, particularly to patients with other risk factors. For example, studies have linked vitamin A supplementation to an increased risk of lung cancer in smokers and zinc supplementation to an increased risk of genitourinary complications. ${ }^{8,9}$ Vitamin E supplementation has been linked to an increased risk of prostate cancer and, in people with vascular disease or diabetes, heart failure. ${ }^{10,11}$

As such, novel RPE protective compounds continue to be of interest for their potential therapeutic value. The present study investigated whether propofol, betaxolol, and N-acetyl cysteine (NAC) can protect RPE cells from tert-butyl hydroperoxide (t-BOOH)-induced oxidative stress. These compounds were selected because they have demonstrated antioxidant properties in other systems. ${ }^{12-14}$ Two established antioxidants for RPE protection, vitamins $\mathrm{C}$ and $\mathrm{E}$, were similarly examined.

\section{Methods}

\section{Reagents}

All cell culture reagents were purchased from Life Technologies (Carlsbad, CA) unless otherwise indicated. Ascorbic acid (vitamin C), ascorbic acid 2-phosphate sesquimagnesium salt hydrate (vitamin $\mathrm{C}$ phosphate), $\alpha$-tocopherol (vitamin E), NAC, t-BOOH, 3-(4,5dimethylthiazol-2-yl)-2,5-diphenyltetrazolium bromide (MTT), and 2,6-diisopropylphenol (propofol) were purchased from Sigma-Aldrich (St Louis, MO). Preservative-free betaxolol was obtained from Alcon (Fort Worth, TX).

\section{ARPE- 19 cell culture}

ARPE-19 cells, which originate from the human RPE, were purchased from the American Type Culture Collection (ATCC, Manassas, VA). The cells were maintained in a 1:1 mixture of Dulbecco's modified Eagle's medium and Ham's F12 medium (DMEM/F12) supplemented with 10\% fetal bovine serum and $1 \%$ penicillin-streptomycin. Cells were incubated at $37^{\circ} \mathrm{C}$ in a $5 \% \mathrm{CO}_{2}$ incubator for 24 hours to allow for $70 \%$ confluence. Cells were then grown in a serum-free medium for another 24 hours. These cells were stored at $-80^{\circ} \mathrm{C}$ for use in the subsequent experiments.

\section{Protective treatments and $\mathrm{t}-\mathrm{BOOH}$ exposure}

Cells were transferred into 96-well plates, with $1 \times 10^{4}$ cells $/ \mathrm{cm}^{2}$, and grown for 48 hours in a serum-containing medium. Cells were then pre-incubated for 1 hour with one of vitamin C (2-200 $\mu \mathrm{M})$, vitamin C phosphate $(4-400 \mu \mathrm{M})$, vitamin E (0.2-0.4 mM), betaxolol (0.1-0.3 mM), NAC (5-10 mM), and propofol $(8-400 \mu \mathrm{M})$. Cells were then placed in an antioxidant-free medium for 1 hour to remove extracellular antioxidants. Finally, the cells were treated for 4 hours with $1 \mathrm{mM}$ t-BOOH in serum-free medium. Dose and time responses of ARPE-19 cells to t-BOOH were characterized using cells which were not pre-incubated with protective compounds. Control cells were not exposed to either protective compounds or t-BOOH.

\section{MTT assay}

The MTT assay was used to determine cell viability. In the presence of viable cells, MTT is enzymatically reduced to the purple dye formazan. The assay was performed according to the manufacturer's instructions. Briefly, cells were incubated in serum-free medium containing $0.4 \mathrm{mg} / \mathrm{mL}$ MTT. After 4 hours, the MTT solution was removed and $0.3 \mathrm{~mL}$ of dimethyl sulfoxide (DMSO) was added to each well to solubilize formazan crystals. Absorbances at $575 \mathrm{~nm}$ were determined using a microplate reader (Spectra Max 340; Molecular Devices, Sunnyvale, CA). Control cells, which represented $100 \%$ viability, were used to normalize absorbances.

\section{Statistical analysis}

The data are reported as the mean \pm standard deviation of three or more experiments. GraphPad Prism 5 (GraphPad Software, Inc, La Jolla, CA) was used to perform statistical analyses. Multigroup comparisons were performed using a one-way ANOVA followed by Bonferroni analysis. A $P$ value of $<0.05$ was considered statistically significant.

\section{Results \\ ARPE- 19 cell viability was reduced by $\mathrm{t}-\mathrm{BOOH}$}

Changes in ARPE-19 cell viability were characterized following t-BOOH exposure. The resultant reduction in cell viability was both dose- and time-dependent (Figure 1). To detect any protective effects of the compounds under investigation, time and dose parameters for $\mathrm{t}-\mathrm{BOOH}$ 

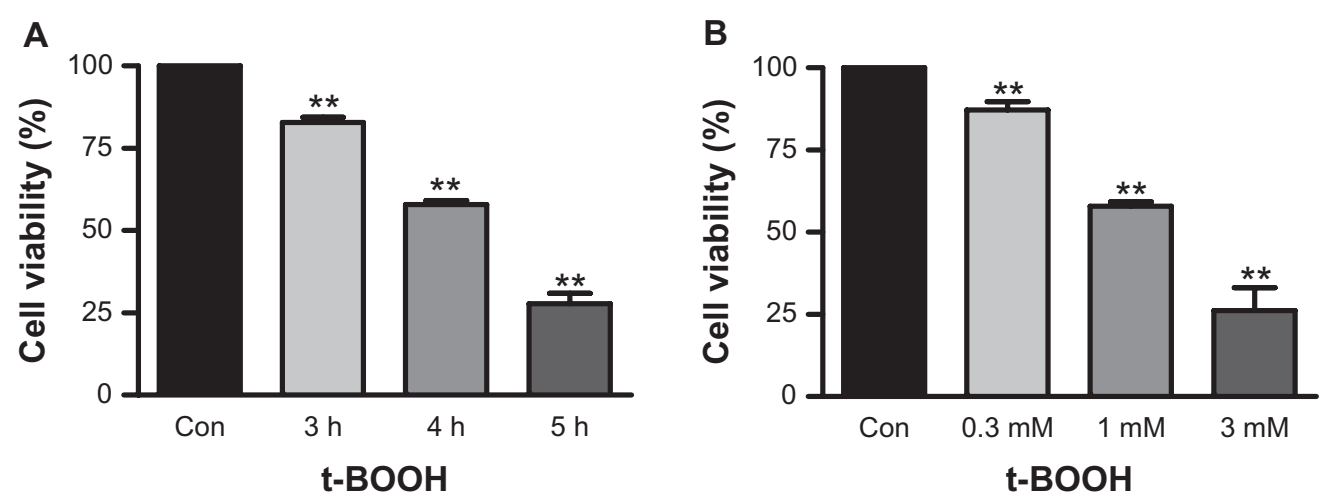

Figure I The response of ARPE- 19 cells to t-BOOH treatment. (A) Cells were treated with I mM t-BOOH for 0-5 hours. (B) Cells were treated for 4 hours with 0-3 mM $\mathrm{t}-\mathrm{BOOH}$. Control cells were not treated with $\mathrm{t}-\mathrm{BOOH}$. Cell viability was determined with the MTT assay. Treatment with t-BOOH resulted in both time- $(\mathbf{A})$ and dosedependent $(\mathbf{B})$ reductions in cell viability.

Note: Asterisks indicate a significant reduction in viability compared with untreated control cells $(* * P<0.00 \mathrm{I})$.

Abbreviations: Con, control cells; t-BOOH, tert-butyl hydroperoxide; MTT, 3-(4,5-dimethylthiazol-2-yl)-2,5-diphenyltetrazolium bromide.

exposure were selected in later experiments to target $60 \%$ cell viability ( $1 \mathrm{mM}, 4$ hours).

\section{Vitamin C and vitamin C phosphate further reduced ARPE-19 cell viability}

There is conflicting evidence regarding the protective effects of vitamin $\mathrm{C}$ in vitro. ${ }^{5,6,15}$ Vitamin $\mathrm{C}$ treatment did not protect RPE cells from oxidative stress in this study, and in fact, further reduced $(P<0.001)$ viability (Figure $2 \mathrm{~A})$. Treatment with vitamin $C$ phosphate also further reduced $(P<0.001)$ ARPE-19 cell viability (Figure 2B). The reduction in cell viability was dose dependent for both forms of vitamin $\mathrm{C}$ (Figure 2A and B).

\section{Vitamin E protected ARPE-I 9 cells from oxidative stress}

The protective effects of vitamin E treatment on RPE cells are well known. ${ }^{3,5,6}$ Vitamin E-treated cells in this study also had significantly greater $(P<0.001)$ viability following $\mathrm{t}-\mathrm{BOOH}$ exposure than unprotected cells (Figure $2 \mathrm{C}$ ). The protective effects of vitamin $\mathrm{E}$ treatment were dose dependent, with a greater than $20 \%$ recovery of ARPE- 19 cell viability at the highest concentration tested $(0.4 \mathrm{mM})$ (Figure $2 \mathrm{C}$ ).

\section{Betaxolol and propofol did not protect ARPE- 19 cells from oxidative stress}

Betaxolol has recently been shown to protect retinal ganglion cells from oxidative stress. ${ }^{13}$ This present study investigated whether betaxolol has similar protective effects for RPE cells. One-hour treatments with either $0.3 \mathrm{mM}$ or $0.5 \mathrm{mM}$ betaxolol did not significantly increase RPE cell viability following t-BOOH exposure (Figure 2D).
Propofol has been found to be neuroprotective following cerebral ischemia. ${ }^{14}$ This effect is hypothesized to be partly due to its antioxidant properties. ${ }^{14}$ This present study examined whether propofol can also protect RPE cells from t-BOOH-induced oxidative stress. Propofol treatment at low doses $(8 \mu \mathrm{M}, 80 \mu \mathrm{M})$ did confer a slight protective effect on ARPE-19 cells, although this was not statistically significant (Figure 2E). A $400 \mathrm{mM}$ treatment with propofol, however, did not result in any increase in cell viability (Figure 2E).

\section{NAC protected ARPE-I 9 cells from oxidative stress}

NAC has been found to have antioxidant properties in many systems. ${ }^{12,16}$ This present study assessed whether pretreatment with NAC would increase ARPE-19 cell viability after t-BOOH exposure. Treatment with $10 \mathrm{mM}$ NAC for 1 hour prior to t-BOOH stress resulted in a significant $(P<0.05)$ improvement in cell viability (Figure $2 \mathrm{~F}$ ). Both tested concentrations of NAC increased ARPE-19 cell viability by approximately $10 \%$ (Figure $2 \mathrm{~F}$ ).

\section{Discussion}

The results of the present study show that both vitamin $\mathrm{E}$ and NAC protect RPE cells from oxidative stress. Pretreatment with either compound significantly increased the viability of t-BOOH-challenged ARPE-19 cells. In terms of relative effectiveness, vitamin $\mathrm{E}$ was markedly more protective than NAC in this study; however, there are disadvantages to its clinical use. The Heart Outcomes Prevention Evaluation (HOPE), for instance, found that a daily dose of vitamin $\mathrm{E}$ may increase the risk of heart failure in patients with vascular disease or diabetes. ${ }^{11}$ More recently, the Selenium and 

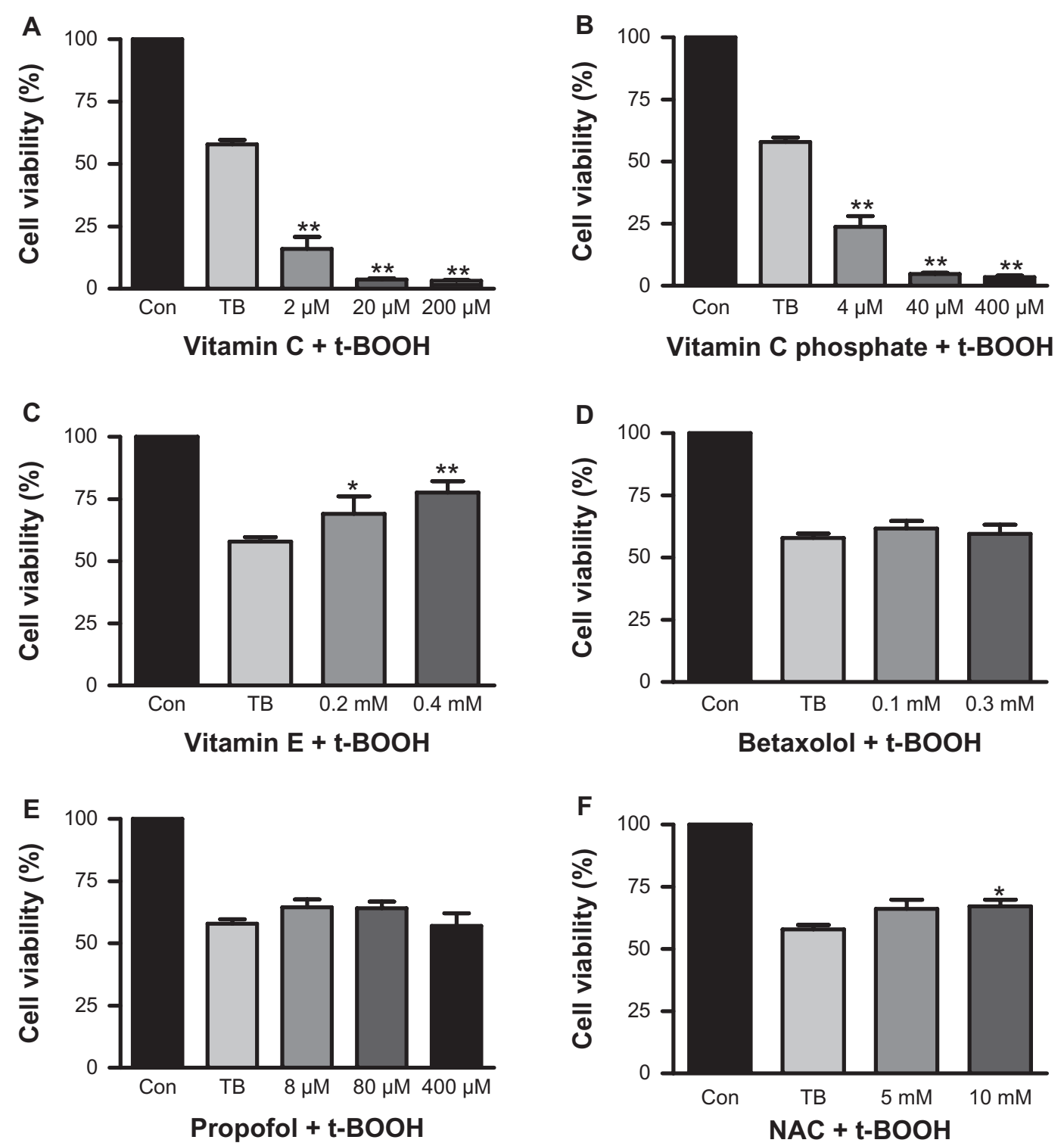

Figure 2 Effects of vitamin C, vitamin C phosphate, vitamin E, betaxolol, propofol, and NAC pretreatment on the viability of oxidatively stressed RPE cells. ARPE-19 cells were incubated with various concentrations of the compounds under investigation for I hour prior to t-BOOH exposure (I mM, 4 hours). Control cells were not treated with either the investigated compounds or $\mathrm{t}-\mathrm{BOOH}$, while other cells were only incubated with t-BOOH. Cell viability was determined with the MTT assay. (A) Vitamin $\mathrm{C}$ pretreatment (ascorbic acid; 2-200 $\mu \mathrm{M}$ ) significantly reduced RPE cell viability following t-BOOH exposure. (B) Vitamin C phosphate pretreatment (ascorbic acid 2-phosphate sesquimagnesium salt hydrate; 4-400 $\mu \mathrm{M}$ ) significantly reduced RPE cell viability following t-BOOH exposure. (C) Vitamin E pretreatment ( $\alpha$-tocopherol; 0.2-0.4 mM) significantly increased RPE cell viability following t-BOOH exposure. (D) Betaxolol pretreatment $(0.1-0.3 \mathrm{mM})$ did not significantly affect RPE cell viability following t-BOOH exposure. (E) Propofol pretreatment $(8-400 \mu \mathrm{M})$ did not significantly affect RPE cell viability following t-BOOH exposure. (F) Pretreatment with I0 mM NAC significantly increased RPE cell viability following t-BOOH exposure.

Notes: Asterisks indicate a significant change in viability compared with cells only treated with t-BOOH $(* P<0.05 ; * * P<0.001)$.

Abbreviations: Con, control cells; NAC, N-acetyl cysteine; RPE, retinal pigment epithelium; TB, t-BOOH; t-BOOH, tert-butyl hydroperoxide; MTT, 3-(4,5-dimethylthiazol-2-yl)2,5-diphenyltetrazolium bromide.

Vitamin E Cancer Prevention Trial (SELECT) found that vitamin E supplementation is associated with an increased risk of prostate cancer. ${ }^{10}$

In contrast, many properties of NAC make it a good candidate drug for AMD patients. NAC is both orally bioavailable and already approved for oral administration in the treatment of acetaminophen overdose. ${ }^{17,18}$ Topical administration of NAC may also be effective; there is evidence that topically applied NAC can penetrate to the posterior segment and protect cone cells from oxidative stress in mice. ${ }^{12}$ Moreover, NAC is already topically administered as an anti-collagenase agent in the treatment of ocular surface alkali burns. ${ }^{19}$ Although the long-term safety of NAC supplementation requires additional study, one in-vivo study did find that mice treated with high-doses of NAC developed pulmonary arterial hypertension. ${ }^{20}$ 
Several mechanisms explain the cytoprotective effects of vitamin $\mathrm{E}$ and NAC. Vitamin E, which has a ROS-scavenging phenol group, is an important chain-breaking antioxidant in cellular membranes. ${ }^{3}$ As a thiol, NAC can reduce oxidative stress by directly scavenging ROS and also acts as a precursor in the biosynthesis of the antioxidant glutathione. ${ }^{21} \mathrm{NAC}$ has been shown to regulate numerous genes, and can directly modify many proteins through its reducing activity. ${ }^{21}$ In RPE cells, NAC inhibits the activation of genes involved in oxidative stress-related apoptosis, such as $p 53$ and CASP $8 .{ }^{22}$

Even though vitamin $\mathrm{C}$ is reported to be protective, ${ }^{5,6}$ in this present study, it had cytotoxic effects. This is unlikely to be $\mathrm{pH}$ related, as it was found that treatment with a vitamin $\mathrm{C}$ phosphate, with reduced acidity, also decreased RPE cell viability. Other investigators have likewise observed increased RPE cell death following vitamin $\mathrm{C}$ treatment. ${ }^{15}$ They suggest that at low concentrations vitamin $\mathrm{C}$ is oxidized by cellular free electrons, producing radicals. ${ }^{15}$ At high concentrations, the formation of radicals would still occur, but they would be rapidly scavenged by the remaining non-oxidized vitamin $\mathrm{C}$ molecules. ${ }^{15}$ The results of this present study are consistent with this hypothesis, the highest concentration of vitamin $\mathrm{C}$ examined being $400 \mu \mathrm{M}$. The dose-dependent reduction in cell viability observed could reflect the formation of additional vitamin $\mathrm{C}$ radicals, but below the threshold concentration at which they would be readily scavenged. It should be noted, however, that others report protective effects with a vitamin $\mathrm{C}$ concentration as low as $100 \mu \mathrm{M} .^{5}$

In this present study, no significant RPE protective effects with betaxolol treatment were observed, even though it has been found to protect retinal ganglion cells from oxidative stress. ${ }^{13}$ Other $\beta$-blockers such as timolol and nipradilol have also been found to protect retinal ganglion cells from oxidative stress and are additional candidates for investigation in RPE cells. ${ }^{13}$ Unlike betaxolol, there was a slight increase in cell viability associated with propofol treatment, although this was also not statistically significant. Different parameters for dose and time may be necessary to observe significant protective effects with either compound.

Care should be exercised when drawing clinical conclusions from in-vitro results; however, given the increasing evidence that NAC protects RPE cells, and its advantages as a candidate drug, NAC merits additional investigation as a retinal protective agent. Vitamin $\mathrm{C}$ may be cytotoxic under certain conditions, and thus should be investigated further before being adopted as a treatment for AMD. Further investigation into RPE protective compounds continues to be necessary, as they have an important role in the treatment of AMD.

\section{Acknowledgments}

The authors would like to thank Dr Sunil Parapuram for his assistance in preparing the manuscript.

\section{Disclosure}

The authors report no conflicts of interest in this work.

\section{References}

1. The Eye Diseases Prevalence Research Group. Causes and prevalence of visual impairment among adults in the United States. Arch Ophthalmol. 2004;122(4):477-485.

2. Roth F, Bindewald A, Holz FG. Key pathophysiologic pathways in age-related macular disease. Graefes Arch Clin Exp Ophthalmol. 2004; 242(8):710-716.

3. Beatty S, Koh H, Henson D, Boulton M. The role of oxidative stress in the pathogenesis of age-related macular degeneration. Surv Ophthalmol. 2000;45(2):115-134.

4. Smith W, Assink J, Klein R, et al. Risk factors for age-related macular degeneration: pooled findings from three continents. Ophthalmology. 2001;108(4):697-704.

5. Hanneken A, Lin FF, Johnson J, Maher P. Flavonoids protect human retinal pigment epithelial cells from oxidative-stress-induced death. Invest Ophthalmol Vis Sci. 2006;47(7):3164-3177.

6. Lu L, Hackett SF, Mincey A, Lai H, Campochiaro PA. Effects of different types of oxidative stress in RPE cells. J Cell Physiol. 2006; 206(1):119-125.

7. Age-Related Eye Disease Study Research Group. A randomized, placebo-controlled, clinical trial of high-dose supplementation with vitamins $\mathrm{C}$ and $\mathrm{E}$, beta carotene, and zinc for age-related macular degeneration and vision loss: AREDS report no. 8. Arch Ophthalmol. 2001;119(10):1417-1436.

8. Omenn GS, Goodman GE, Thornquist MD, et al. Effects of a combination of beta-carotene and vitamin A on lung cancer and cardiovascular disease. $N$ Engl J Med. 1996;334(18):1150-1155.

9. Johnson AR, Munoz A, Gottlieb JL, Jarrard DF. High dose zinc increases hospital admissions due to genitourinary complications. J Urol. 2007;177(2):639-643.

10. Klein EA, Thompson IM Jr, Tangen CM, et al. Vitamin E and the risk of prostate cancer: the Selenium and Vitamin E Cancer Prevention Trial (SELECT). JAMA. 2011;306(14):1549-1556.

11. The HOPE and HOPE-TOO Trial Investigators. Effects of long-term vitamin E supplementation on cardiovascular events and cancer: a randomized control trial. JAMA. 2005;293(11):1338-1347.

12. Lee SY, Usui S, Zafar AB, et al. N-acetylcysteine promotes long-term survival of cones in a model of retinitis pigmentosa. J Cell Physiol. 2011;226(7):1843-1849.

13. Yu ZK, Chen YN, Aihara M, Mao W, Uchida S, Araie M. Effects of beta-adrenergic receptor antagonists on oxidative stress in purified rat retinal ganglion cells. Mol Vis. 2007;13:833-839.

14. Vanlersberghe C, Camu F. Propofol. Handb Exp Pharmacol. 2008;182: 227-252.

15. Zeitz O, Schlichting L, Richard G, Strauss O. Lack of antioxidative properties of vitamin $\mathrm{C}$ and pyruvate in cultured retinal pigment epithelial cells. Graefes Arch Clin Exp Ophthalmol. 2007;245(2):276-281.

16. Eichler W, Reiche A, Yafai Y, Lange J, Wiedemann P. Growth-related effects of oxidant-induced stress on cultured RPE and choroidal endothelial cells. Exp Eye Res. 2008;87(4):342-348.

17. Dilger RN, Baker DH. Oral N-acetyl-L-cysteine is a safe and effective precursor of cysteine. J Anim Sci. 2007;85(7):1712-1718. 
18. Kanter MZ. Comparison of oral and i.v. acetylcysteine in the treatment of acetaminophen poisoning. Am J Health Syst Pharm. 2006;63(19): 1821-1827.

19. Gicquel JJ. Management of ocular surface chemical burns. $\mathrm{Br} J$ Ophthalmol. 2011;95(2):159-161.

20. Palmer LA, Doctor A, Chhabra P, et al. S-Nitrosothiols signal hypoxiamimetic vascular pathology. J Clin Invest. 2007;117(9):2592-2601.
21. Zafarullah M, Li WQ, Sylvester J, Ahmad M. Molecular mechanisms of N-acetylcysteine actions. Cell Mol Life Sci. 2003;60(1):6-20.

22. Gerona G, López D, Palmero M, Maneu V. Antioxidant N-acetyl cysteine protects retinal pigmental epithelial cells from long-term hypoxia changes in gene expression. J Ocul Pharmacol Ther. 2010; 26(4):309-314.

\section{Publish your work in this journal}

Clinical Ophthalmology is an international, peer-reviewed journal covering all subspecialties within ophthalmology. Key topics include: Optometry; Visual science; Pharmacology and drug therapy in eye diseases; Basic Sciences; Primary and Secondary eye care; Patient Safety and Quality of Care Improvements. This journal is indexed on

\section{Dovepress}

PubMed Central and CAS, and is the official journal of The Society of Clinical Ophthalmology (SCO). The manuscript management system is completely online and includes a very quick and fair peer-review system, which is all easy to use. Visit http://www.dovepress.com/ testimonials.php to read real quotes from published authors. 